Article

\title{
Epidermal Growth Factor Enhances Cellular Uptake of Polystyrene Nanoparticles by Clathrin-Mediated Endocytosis
}

\author{
Le Thi Minh Phuc ${ }^{1,2}$ and Akiyoshi Taniguchi ${ }^{1,2, *}$ \\ 1 Cellular Functional Nanomaterials Group, Research Center for Functional Materials, \\ National Institute for Materials Science, 1-1 Namiki, Tsukuba, Ibaraki 305-0044, Japan; \\ lethiminh.phuc@nims.go.jp \\ 2 Graduate School of Advanced Science and Engineering, Waseda University, 3-4-1 Okubo, Shinjuku-ku, \\ Tokyo 169-8555, Japan \\ * Correspondence: taniguchi.akiyoshi@nims.go.jp; Tel.: +81-29-860-4505
}

Academic Editor: Ivo Iavicoli

Received: 2 May 2017; Accepted: 14 June 2017; Published: 19 June 2017

\begin{abstract}
The interaction between nanoparticles and cells has been studied extensively, but most research has focused on the effect of various nanoparticle characteristics, such as size, morphology, and surface charge, on the cellular uptake of nanoparticles. In contrast, there have been very few studies to assess the influence of cellular factors, such as growth factor responses, on the cellular uptake efficiency of nanoparticles. The aim of this study was to clarify the effects of epidermal growth factor (EGF) on the uptake efficiency of polystyrene nanoparticles (PS NPs) by A431 cells, a human carcinoma epithelial cell line. The results showed that EGF enhanced the uptake efficiency of A431 cells for PS NPs. In addition, inhibition and localization studies of PS NPs and EGF receptors (EGFRs) indicated that cellular uptake of PS NPs is related to the binding of EGF-EGFR complex and PS NPs. Different pathways are used to enter the cells depending on the presence or absence of EGF. In the presence of EGF, cellular uptake of PS NPs is via clathrin-mediated endocytosis, whereas, in the absence of EGF, uptake of PS NPs does not involve clathrin-mediated endocytosis. Our findings indicate that EGF enhances cellular uptake of PS NPs by clathrin-mediated endocytosis. This result could be important for developing safe nanoparticles and their safe use in medical applications.
\end{abstract}

Keywords: EGF; PS NPs; cellular uptake; clathrin-mediated endocytosis

\section{Introduction}

Polystyrene nanoparticles (PS NPs) are widely used as a model for studying the interaction between NPs and cells due to their many advantages, including commercial availability, high quality, diverse sizes and shapes, biocompatibility, biological non-toxicity, and high functionality due to the presence of many chemical groups [1-3]. PS NPs are utilized in various research and commercial applications, including biosensors [4], photonics [5], self-assembling nanostructures [6], and spray and exterior paints [7]. The increasingly wide use of PS NPs is leading to a corresponding rise in exposure levels, thereby raising the problem of potential risk to human health. It is therefore essential to investigate potential interactions between PS NPs and cells.

Most PS NPs are less than $100 \mathrm{~nm}$ in diameter and could potentially enter mammalian cells [2]. Indeed, PS NPs have been reported to internalize in many types of cells, such as hepatocyte [8], macrophage [9], lung [10], and epithelium [11]. Previous studies showed that PS NPs can enter cells by several pathways, including phagocytosis, clathrin-coated vesicles, caveolae-mediated endocytosis, and macropinocytosis [12-14]. The internalization of NPs is affected by a variety of NP factors, such as 
target dose, particle size, cell type, NP morphology and surface chemistry, NP geometry, and also by cellular responses, such as the cell cycle phase [15-20]. However, few studies have assessed the potentially important effects of cellular responses on the uptake efficiency of PS NPs.

Increased synthesis of epidermal growth factor (EGF) is induced by several cellular responses, including epithelial cell growth. The aim of this study was to clarify how EGF affects the uptake by A431 human carcinoma epithelial cells of PS NPs. EGF is widely used for studying cellular responses and acts by binding to its specific receptor, epidermal growth factor receptor (EGFR), on the cell surface [21,22]. The A431 cell line expresses high levels of EGF receptors on the cell surface $\left(2-3 \times 10^{6}\right.$ receptors/cell) $[23,24]$, and thus their adaptation with EGF could lead to changes in the cellular uptake ratio and pathway of PS NPs. Our results indicate that EGF enhances the uptake efficiency of PS NPs by clathrin-mediated endocytosis, inducing the aggregation of EGF receptors on the cell membrane surface. These results could be important for developing safe NPs and their safe use in medical applications.

\section{Materials and Methods}

\subsection{Cell Culture}

The A431 cell line (JCRB Bank, Osaka, Japan) was cultured at $37^{\circ} \mathrm{C}, 5 \% \mathrm{CO}_{2}$, in high glucose Dulbecco's modified Eagle medium (DMEM, Nacalai Tesque, Kyoto, Japan) supplemented with $10 \%(v / v)$ fetal bovine serum (FBS, Biowest, Tokyo, Japan), $100 \mu \mathrm{g} / \mathrm{mL}$ penicillin, and $10 \mu \mathrm{g} / \mathrm{mL}$ streptomycin. The cells were subcultured every 2 days when confluency reached $70-80 \%$.

\subsection{Characteristics of PS NPS}

Fluoresbrite ${ }^{\circledR}$ YG Microspheres $(0.05 \mu \mathrm{m})$ were bought from Polysciences (Warrington, PA, USA). Their size distribution and stability were analyzed using an electronic light scattering (ELS) detector (ELSZ-2000 ELS, zeta potential, and particle size analyzer, Otsuka Electronics, Osaka, Japan). The results confirmed that the PS NPs were $44.9 \pm 10.5 \mathrm{~nm}$ in diameter, with a low polydispersity index of 0.053 and a zeta potential of $-46.68 \mathrm{mV}$ in culture medium including $10 \%$ FBS.

\subsection{Cellular Uptake of NPs and Inhibition Study}

The cellular percent uptake of PS NPs by A431 cells was calculated from the fluorescence intensity of cells containing fluorescently labeled PS NPs. Briefly, A431 cells were seeded at a density $5 \times 10^{5}$ cells $/ \mathrm{mL}$ in a 6-well plate and incubated at $37^{\circ} \mathrm{C}, 5 \% \mathrm{CO}_{2}$, for $24 \mathrm{~h}$. Next, the cells were incubated in medium containing $10 \mu \mathrm{g} / \mathrm{mL} \mathrm{NPs}$ with or without EGF $(100 \mathrm{ng} / \mathrm{mL})$ for $24 \mathrm{~h}$. Cells untreated with either NPs or EGF were used as control. The cells were washed twice with phosphate buffered saline (PBS) $1 \times$ to completely remove excess NPs. The harvested cells were treated with trypsin/EDTA for $12 \mathrm{~min}$, centrifuged at $1200 \mathrm{rpm}$ for $3 \mathrm{~min}$, and then the cell debris was suspended in $1 \mathrm{~mL}$ PBS 1×. Cellular uptake was measured using a SP6800 Spectral Analyzer (Sony Biotechnology Inc., Tokyo, Japan).

Inhibition studies were performed by washing the cells twice with PBS and pretreating with $0.45 \mathrm{M}$ sucrose in serum-free medium for $1 \mathrm{~h}$ at $37^{\circ} \mathrm{C}$, then medium containing $10 \mu \mathrm{g} / \mathrm{mL}$ nanoparticles with or without $100 \mathrm{ng} / \mathrm{mL}$ EGF was added and the cells were incubated for $24 \mathrm{~h}$ at $37^{\circ} \mathrm{C}$ in the presence of $0.45 \mathrm{M}$ sucrose. The effect of anti-EGFR antibody on EGF-dependent cellular uptake enhancement was determined by exposing cells to $20 \mathrm{ng} / \mathrm{mL}$ anti-EGFR antibody either alone or in combination with $100 \mathrm{ng} / \mathrm{mL}$ EGF for $24 \mathrm{~h}$ at $37^{\circ} \mathrm{C}$. Finally, the A431 cells were washed, harvested, and assessed as described above for determining cellular uptake of NPs.

\subsection{Distribution of EGF Receptors on the Cell Membrane Surface}

The distribution of EGF receptors (EGFRs) on the cell membrane surface was determined using fluorescently labeled anti-EGFR antibody. First, A431 cells were plated in a CELLview cell culture dish 
(Greiner Bio-one North America Inc., Carolina, NC, USA) at a density $2.5 \times 10^{4}$ cells per compartment for $24 \mathrm{~h}$. Then, the cells were washed with PBS X1, fixed with $4 \%$ formaldehyde for $10 \mathrm{~min}$ at $37^{\circ} \mathrm{C}$, permeabilized with $0.1 \%$ Triton X-100 for $5 \mathrm{~min}$, and then blocked with $1 \% \mathrm{BSA} / 10 \%$ normal goat serum $/ 0.3 \mathrm{M}$ glycine in $0.1 \%$ PBS-Tween for $1 \mathrm{~h}$. The cells were then incubated overnight at $4{ }^{\circ} \mathrm{C}$ with fluorescently labeled anti-EGFR antibody (Abcam, London, UK). Nuclear DNA was labeled with DAPI (4',6-diamidino-2-phenylindole) (Thermo Fisher Scientific, Waltham, MA, USA) and images were obtained with a confocal laser-scanning microscope (LSM510 META, Carl Zeiss Inc., Jena, Germany).

\subsection{Statistics Analysis}

All data were assessed for statistical significance using a statistical software program (Microcal Origin 8.1, Microcal Software Inc., Northampton, MA, USA). The differences between the mean values of different groups were determined using one-way ANOVA with Tukey test. All values are presented as mean \pm S.D. with at least 3 independent replicates $(n \geq 3) .{ }^{*} p \leq 0.05,{ }^{* *} p \leq 0.01,{ }^{* * *} p \leq 0.001$, as indicated in the figure legends.

\section{Results}

\subsection{Dose-Dependent Cellular Uptake of PS NPs by A431 Cells}

To determine the influence of NP dosage on uptake efficiency, A431 cells were exposed to six concentrations of PS NPs $(10,20,50,100,200$ and $500 \mu \mathrm{g} / \mathrm{mL})$ at $37^{\circ} \mathrm{C}$ for $24 \mathrm{~h}$. As shown in Figure 1, uptake efficiency increased in a dose-dependent manner similar to the Michaelis-Menten equation from 0 to $100 \mu \mathrm{g} / \mathrm{mL}$ PS NPs, and then plateaued at concentrations $\geq 100 \mu \mathrm{g} / \mathrm{mL}$ PS NPs. These results suggested that this concentration $\left(10 \mu \mathrm{g} / \mathrm{mL} ; 1.5 \times 10^{11} \mathrm{NPs} / \mathrm{mL}\right)$ was a good compromise between an observable effect and a condition far to saturation.

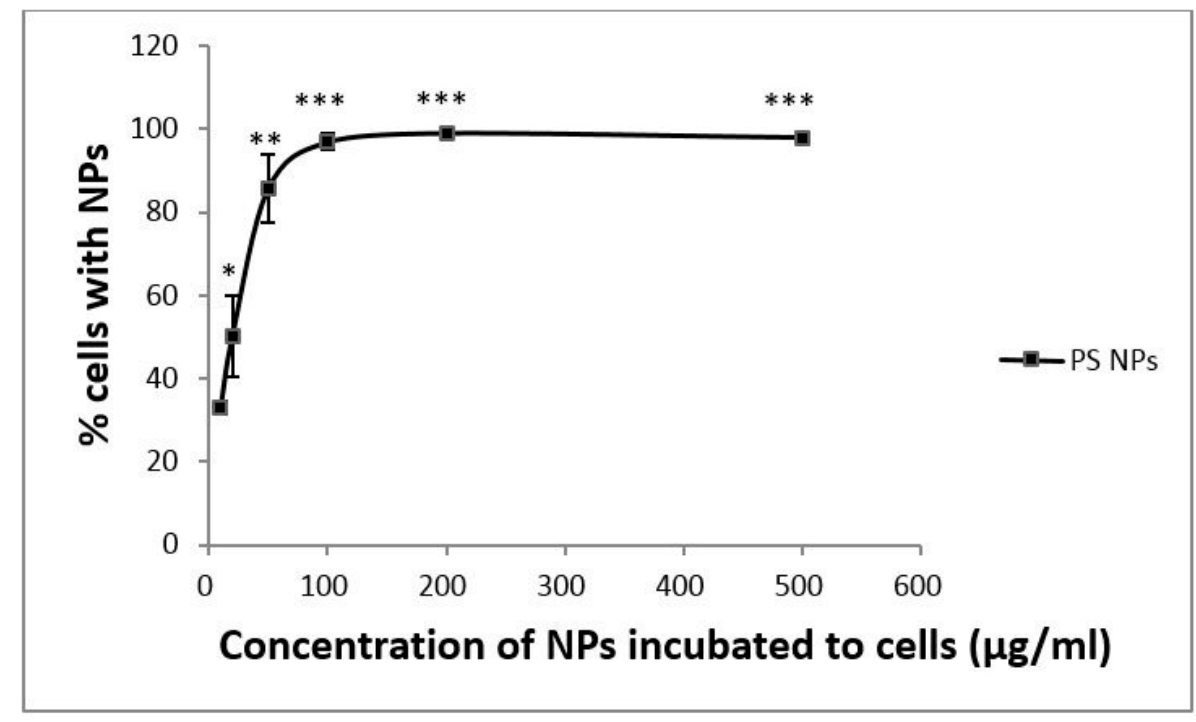

Figure 1. Dose dependency of PS NP cellular uptake by A431 cells. A431 cells were treated with different concentrations of PS NPs $(10,20,50,100,200$ and $500 \mu \mathrm{g} / \mathrm{mL})$ at $37^{\circ} \mathrm{C}$ for $24 \mathrm{~h}$. The cellular uptake efficiency of NPs was normalized to that of untreated control cells. Mean values \pm standard deviation, $n=3 .{ }^{*} p \leq 0.05,{ }^{* *} p \leq 0.01,{ }^{* *} p \leq 0.001$ compared to each normalized control.

\subsection{EGF Enhanced Cellular Uptake of PS NPs}

The effect of EGF on the cellular uptake of PS NPs by A431 cells was examined and the results are shown in Figure 2. The percentage of control cells containing NPs was approximately $30 \%$, whereas the cellular uptake ratio of PS NPs by cells treated with $100 \mathrm{ng} / \mathrm{mL}$ of EGF increased to approximately $70 \%$. EGF enhanced cellular uptake of PS NPs by dose dependent manor (data not shown), and 
$100 \mathrm{ng} / \mathrm{mL}$ of EGF showed higher enhancing than lower concentration of EGF. We confirmed the increase in cellular uptake by EGF and EGFR by adding anti-EGFR antibody, which blocks the binding of EGF to EGFR. We first tested the effect of anti-EGFR antibody $(20 \mathrm{ng} / \mathrm{mL})$ alone or in combination with EGF (100 ng/mL). Treatment with anti-EGFR antibody $(20 \mathrm{ng} / \mathrm{mL})$ alone had no significant effect on the uptake ratio of PS NPs by A431 cells, whereas treatment with a combination of EGF and anti-EGFR antibody significantly decreased the uptake ratio. Anti-EGFR antibody blocked cellular uptake by dose dependent manor (data not shown), and $20 \mathrm{ng} / \mathrm{mL}$ of anti-EGFR antibody showed higher blocking effects than lower concentration of antibody. The results suggested that the EGF-EGFR complex participates in cellular uptake triggered by an increase in EGF.

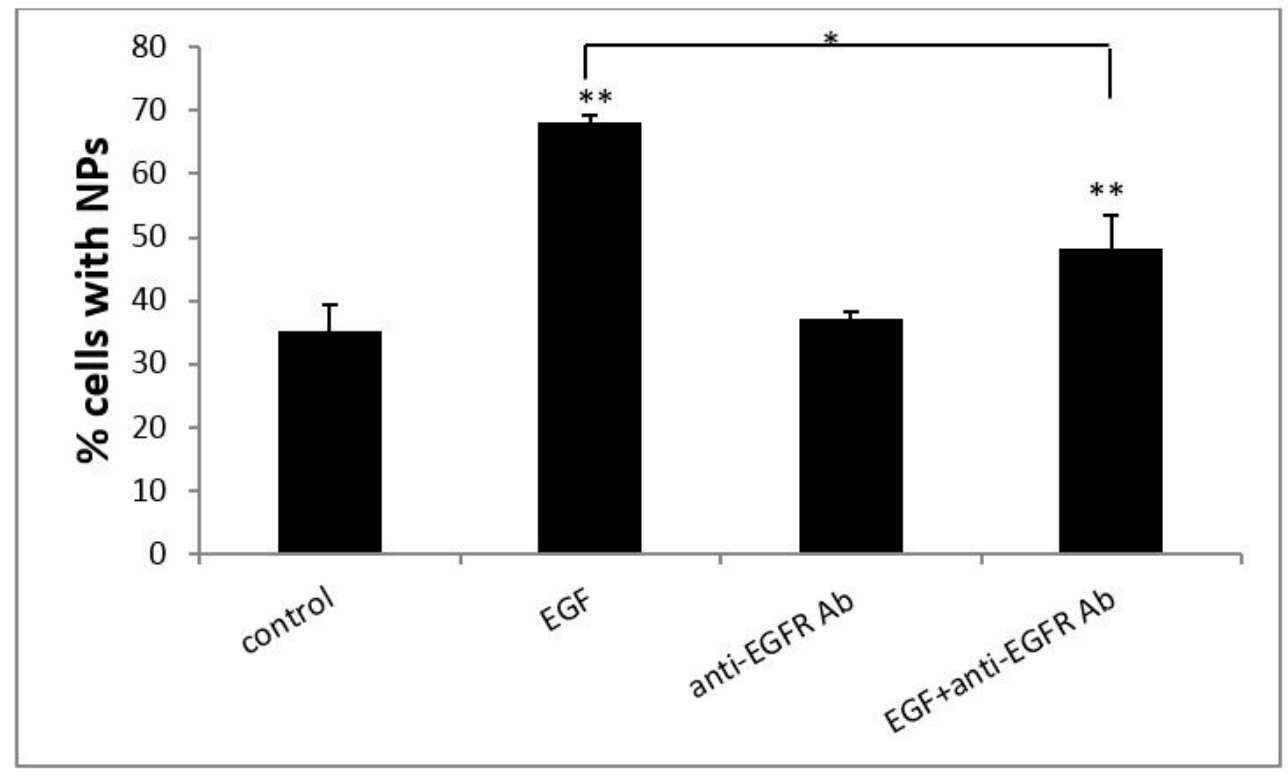

Figure 2. EGF enhanced PS NP cellular uptake efficiency by A431 cells. A431 cells were incubated with $100 \mathrm{ng} / \mathrm{mL}$ of EGF (second bar), $20 \mathrm{ng} / \mathrm{mL}$ of anti-EGFR antibody (third bar), or $100 \mathrm{ng} / \mathrm{mL}$ of EGF and $20 \mathrm{ng} / \mathrm{mL}$ of anti-EGFR antibody (fourth bar) at $37^{\circ} \mathrm{C}$ for $24 \mathrm{~h}$. The cellular uptake efficiency of NPs was normalized to that of untreated control cells (first bar). Mean values \pm standard deviation, $n=3 .{ }^{*} p \leq 0.05,{ }^{* *} p \leq 0.01$ compared to each normalized control.

\subsection{The Cellular Uptake of PS NPs by EGF Induction Occurs through Clathrin-Mediated Endocytosis}

Several cellular pathways could be involved in the process of internalizing NPs, such as phagocytosis and endocytosis. To further elucidate the mechanism of cellular uptake of PS NPs, cells were incubated in hyperosmotic sucrose solution to inhibit clathrin-mediated endocytosis. A431 cells were incubated with PS NPs with or without EGF $(100 \mathrm{ng} / \mathrm{mL})$ and with or without sucrose solution $(0.45 \mathrm{M})$. As shown in Figure 3, the uptake ratio of PS NPs was significantly reduced in cells treated with sucrose and EGF (right gray bar), similar to that of cells not treated with EGF. These results showed that sucrose decreased the effect of EGF on cellular uptake of PS NPs. In contrast, in cells treated with sucrose but not EGF (left gray bar), the ratio of cellular uptake was similar to that of the control cells. This result indicated that PS NPs used different pathways to enter the cells in the presence or absence of EGF. In the presence of EGF, cellular uptake of PS NPs was via clathrin-mediated endocytosis, whereas, in the absence of EGF, uptake of PS NPs did not involve clathrin-mediated endocytosis. Consequently, EGF enhanced cellular uptake of PS NPs by clathrin-mediated endocytosis. Sucrose is known to disrupt the formation of clathrin-vesicles, and thus cellular uptake triggered by EGF was predominantly via endocytosis involving clathrin-coated vesicles. However, in the absence of EGF, NPs were taken up via another pathway, independent of clathrin-coated vesicles. 


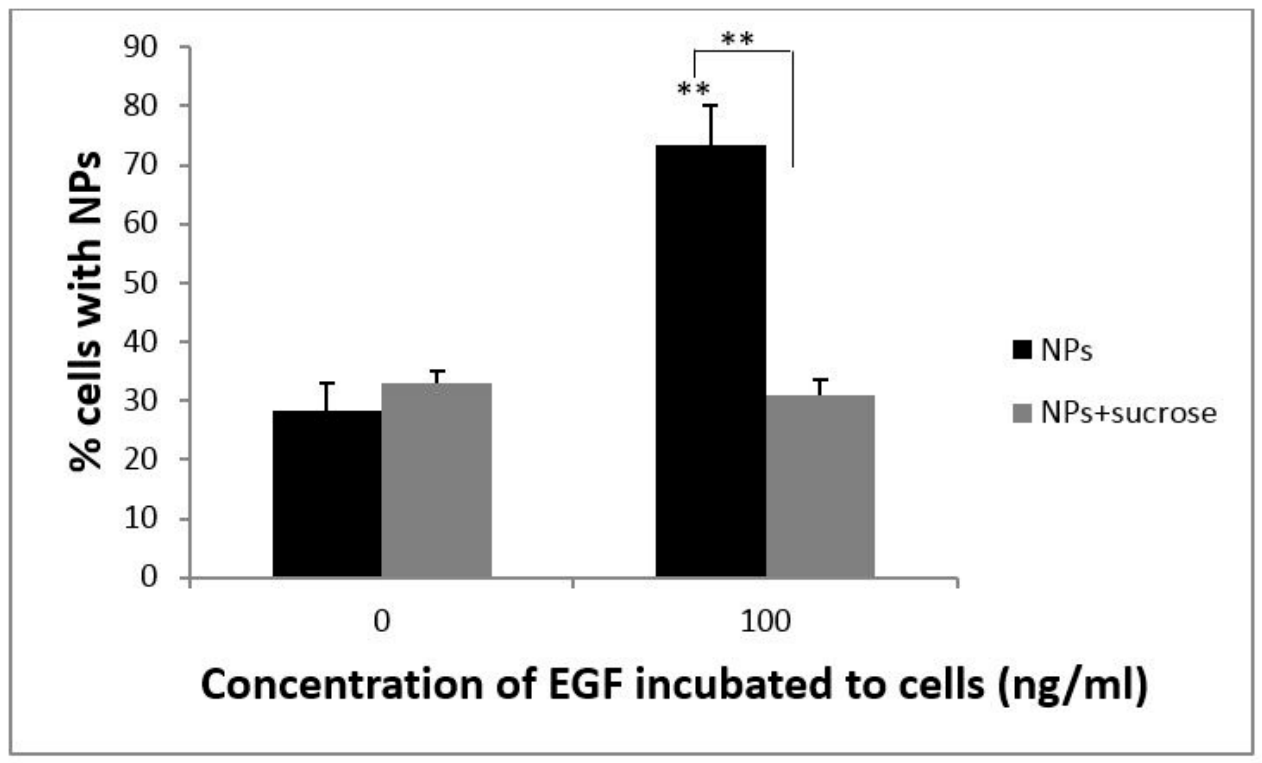

Figure 3. Effect of sucrose on cellular uptake efficiency of PS NPs. A431 cells were exposed to $10 \mu \mathrm{g} / \mathrm{mL}$ of PS NPs and $100 \mathrm{ng} / \mathrm{mL}$ EGF with (gray bars) or without (black bars) $0.45 \mathrm{M}$ sucrose, at $37^{\circ} \mathrm{C}$ for $24 \mathrm{~h}$. The cellular uptake efficiency of NPs was normalized to that of untreated control cells. Mean values \pm standard deviation, $n=3{ }^{* *} p \leq 0.01$ compared to each normalized control.

\subsection{The Localization of EGFRs and PS NPs in A431 Cells with or without EGF}

We confirmed the role of EGF and EGFR in PS NP cellular uptake by localizing the EGFRs and PS NPs by confocal microscopy. The results indicated that without EGF, EGFRs were distributed homogeneously on the cell membrane (Figure 4A). In contrast, EGF induced changes in the localization of EGFRs: in the presence of $100 \mathrm{ng} / \mathrm{mL}$ EGF, EGFR aggregated slightly and formed several receptor clusters on the cell surface, and EGFR was also detected in the cytoplasm (Figure 4B). When cells were exposed to EGF and PS NPs, EGFR and PS NPs co-localized in the cytoplasm (Figure 4C), indicating that cellular uptake of PS NPs involves the binding of aggregated EGF-EGFR complexes and PS NPs. Sometime, labeled NPs had different character with none-labeled one. We could not deny fluorescent label affected to EGF-EGFR complexes.
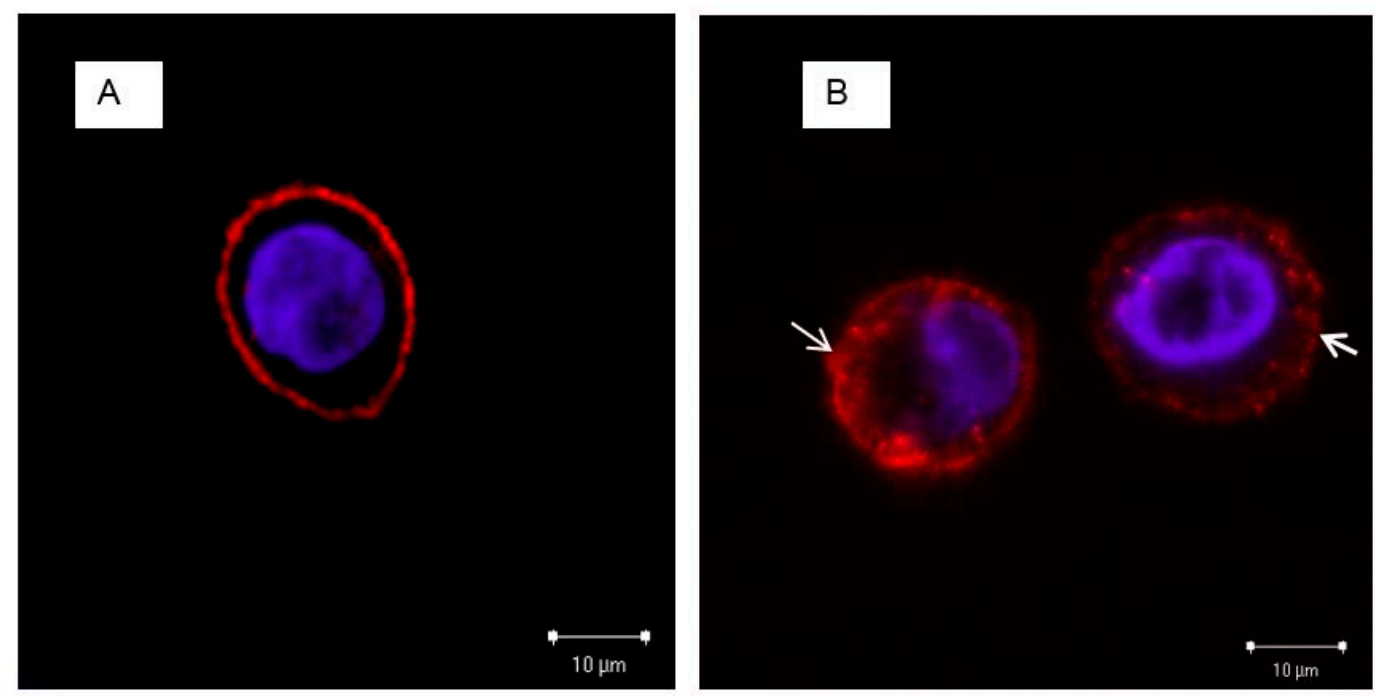

Figure 4. Cont. 


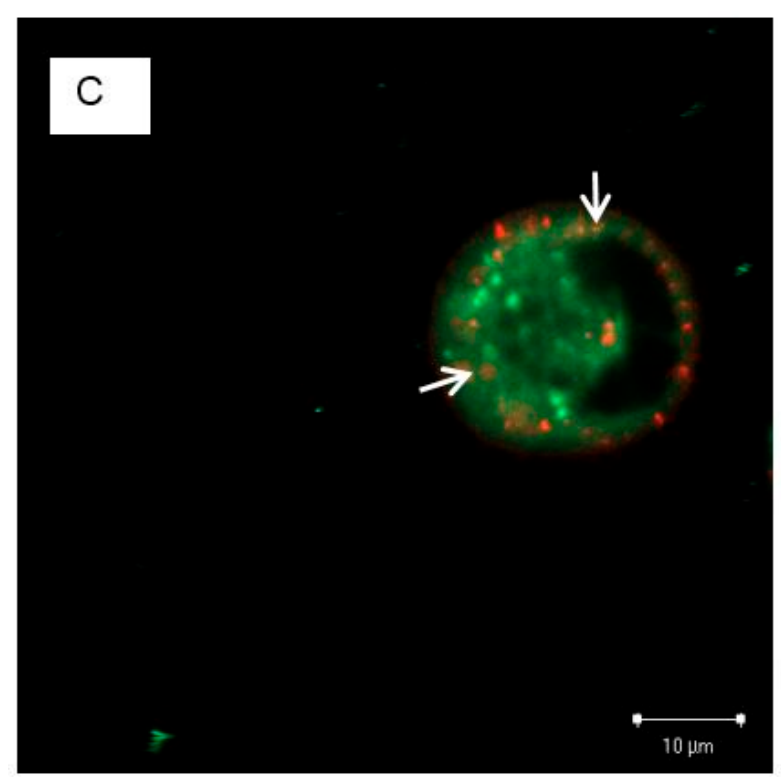

Figure 4. Localization of EGFR and PS NPs in A431 cells. Typical three-color merged confocal fluorescence microscopy images of A431 cells stained with: (A) anti-EGFR antibody; or exposed to: (B) $100 \mathrm{ng} / \mathrm{mL}$ EGF; or (C) $100 \mathrm{ng} / \mathrm{mL}$ EGF + $10 \mu \mathrm{g} / \mathrm{mL}$ NPs. Without EGF, EGFR distributed homogeneously on the cell membrane. In the presence of EGF, EGF induced slight aggregation of EGFRs. The presence of EGF and PS NPs resulted in co-localization of EGFRs and NPs in the cytoplasm. EGFRs are shown in red, NPs in green, and the cell nucleus (stained with DAPI) in blue.

\section{Discussion and Conclusions}

In this work, we studied the effects of EGF on cellular uptake and clarified the principal cellular uptake pathway of PS NPs. First, A431 cells were exposed to different concentrations of PS NPs and the cellular uptake ratio was determined using flow cytometry. The result showed that the uptake of PS NPs increased in a PS NP dose-dependent manner. Next, we also investigated the binding inhibition of EGF to EGFR by anti-EGFR antibody and observed that anti-EGFR antibody decreased the uptake efficiency of NPs into cells. Typically, after binding to a ligand such as EGF, EGFR forms homodimers or heterodimers with other members of the ErbB family of receptor tyrosine kinases (RTKs), thereby activating various downstream signaling pathways [25]. Anti-EGFR antibody would compete with EGF to bind to EGFR. This inhibition would reduce the number of receptor clusters and lead to decreased particle uptake efficiency. In addition, the effect of EGF on the internalization of PS NPs was examined. A previous study showed that at high concentration $(\geq 0.3 \mathrm{nM})$, EGF inhibited the growth of A431 cells [1], and thus changes in the growth of cells caused by EGF could affect their ability to uptake particles. Therefore, in this study a high concentration of EGF $(100 \mathrm{ng} / \mathrm{mL})$ was used. The flow cytometry results revealed that a high dose of EGF enhanced PS NP uptake into the cells. To determine the cellular uptake pathway, we added sucrose, which is known to disrupt the formation of clathrin vesicles [26-28]. We observed that sucrose significantly decreased the uptake ratio of NPs when a high concentration of EGF was present, whereas no difference in uptake efficiency was observed without added EGF. These findings indicate that cellular uptake of PS NPs is enhanced by EGF, and PS NPs use different pathways to enter cells, dependent or independent of clathrin-mediated endocytosis, corresponding to the presence or absence of added EGF.

Our hypothesis explaining the observed differences in uptake efficiency of PS NPs by A431 cells is shown in Figure 5. When cells are incubated with a high concentration of EGF, EGF induces EGFR aggregation and receptor clustering. Previous studies concluded that stimulation with $100 \mathrm{ng} / \mathrm{mL}$ EGF caused EGFR aggregation on the plasma membrane, followed by receptor internalization after longer stimulation times $[29,30]$. In the present study, we observed that PS NPs could combine with 
the EGF-EGFR complex and be internalized by A431 cells by clathrin-mediated endocytosis together with the EGF-EGFR complex, resulting in a large number of internalized PS NPs. In contrast, in the absence of EGF, few PS NPs would be internalized through the endocytosis pathway, independent of the EGF-EGFR complex. When the culture medium did not contain EGF, the EGFRs were distributed homogeneously on the cell surface (Figure 4A), whereas EGFRs slightly aggregated in the presence of a high concentration of EGF (Figure 4B). EGFRs and NPs co-localized in the cytoplasm of cells exposed to $100 \mathrm{ng} / \mathrm{mL}$ EGF and NPs (Figure 4C). Therefore, our results show that EGF enhances the cellular uptake of PS NPs by promoting the aggregation of EGFRs and by binding PS NPs to the EGF-EGFR complex via clathrin-mediated endocytosis. The other possibility is the EGF protein would associate with the NPs first, leading to their enhanced association with EGFR. To provef this hypothesis, direct evidence for the interaction between PS NPs and EGF-EGFR complex could be needed.

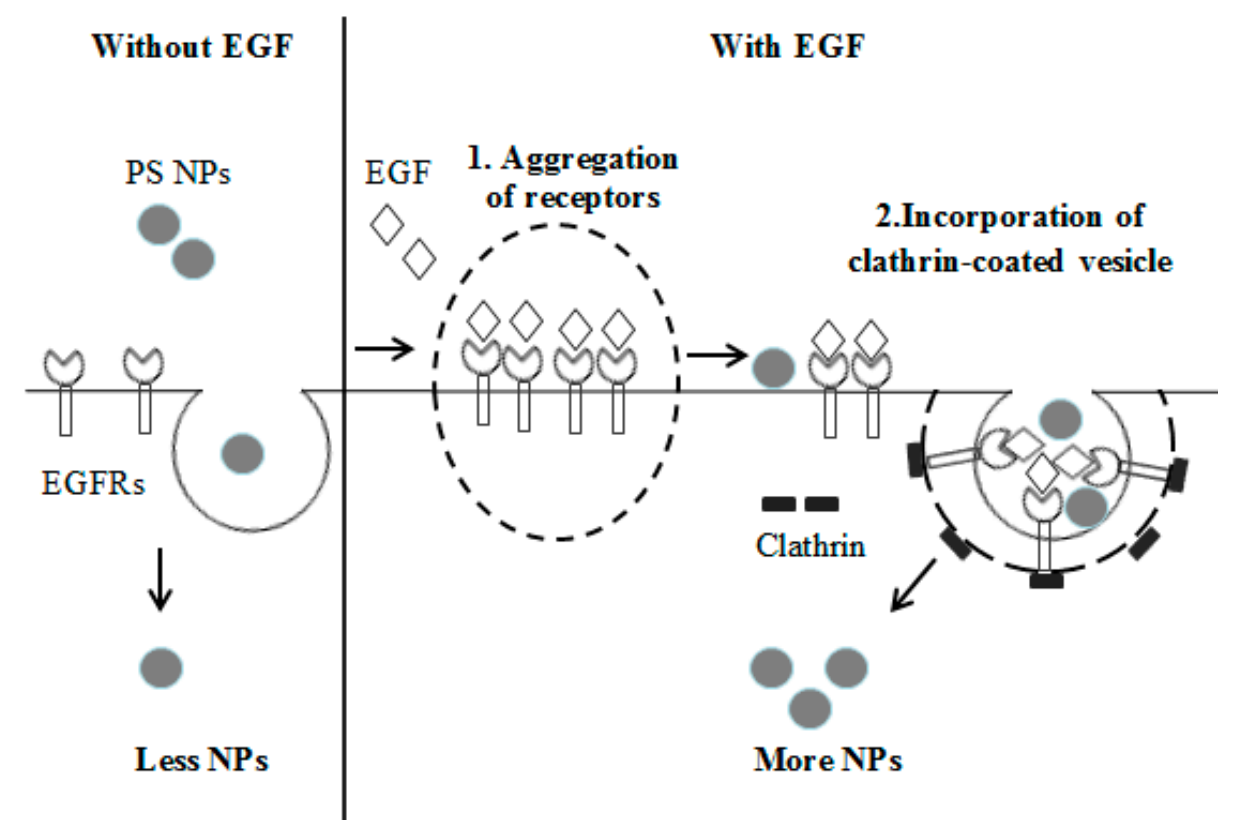

Figure 5. Hypothesis explaining the molecular mechanism for cellular uptake of PS NPs. When culture medium lacks EGF, most PS NPs pass through the cell membrane via the endocytosis pathway. In the presence of added EGF, the aggregation of EGFRs provides more space on the cell membrane, allowing NPs to enter the cells easier, and also NPs could combine with the EGF-EGFR complex, allowing their uptake into the cells through clathrin-mediated endocytosis.

Acknowledgments: We thank Shinya Hattori and Hiromi Morita of the NIMS Molecule \& Material Synthesis Platform for assistance in obtaining and analyzing the flow cytometry results.

Author Contributions: Le Thi Minh Phuc did most part of experiments, and wrote the initial draft of the manuscript. Akiyoshi Taniguchi contributed to design the study, and assisted in the preparation of the manuscript. All authors have contributed to data collection and interpretation, and critically reviewed the manuscript. All authors approved the final version of the manuscript, and agree to be accountable for all aspects of the work in ensuring that questions related to the accuracy or integrity of any part of the work are appropriately investigated and resolved.

Conflicts of Interest: The authors declare no conflict of interest.

\section{References}

1. Cornelia, L.; Tatiana, S.; Anna, M.; Volker, M.; Katharina, L.; Ulrich, G.N.; Thomas, S. Functionalized polystyrene nanoparticles as a platform for studying bio-nano interactions. Beilstein J. Nanotechnol. 2014, 5, 2403-2412. 
2. Juan, A.V.; Mariana, G.B.; Christoffer, Å.; Jeremy, C.S.; Kenneth, A.D. Quantifying size-dependent interactions between fluorescent labeled polystyrene nanoparticles and mammalian cells. J. Nanobiotechnol. 2012, 10, 39.

3. Eleonore, F.; Claudia, M.; Eva, R.; Birgit, E.; Markus, A.; Thomas, R.P. Action of polystyrene nanoparticles of different sizes on lysosomal function and integrity. Part Fibre Toxicol. 2012, 9, 26.

4. Orlin, D.V.; Kaler, E.W. In situ assembly of colloidal particles into miniaturized biosensors. Langmuir 1999, 15, 3693-3698.

5. Rogach, A.; Susha, A.; Caruso, F.; Sukhorukov, G.; Kornowski, A.; Kershaw, S.; Möhwald, H.; Eychmüller, A.; Weller, H. Nano- and microengineering: 3-D colloidal photonic crystals prepared from sub- $\mu$-sized polystyrene latex spheres precoated with luminescent polyelectrolyte/Nanocrystal shells. Adv. Mater. 2000, 12, 333-337. [CrossRef]

6. Andrew, K.B.; Faysal, 1.; Jason, E.D.; Thomas, T.; Thomas, P.R.; Vincent, M.R. Self-assembly of nanoparticles into structured spherical and network aggregates. Nature 2000, 404, 746-748.

7. Phosphores Microsphere, Nanoparticles \& Drug Delivery. Available online: http:/ /www.phosphorex.com/ 1/post/2013/07/commercial-applications-use-polystyrene-nanoparticles.html (accessed on 17 April 2017).

8. Johnston, H.J.; Semmler-Behnke, M.; Brown, D.M.; Kreyling, W.; Tran, L.; Stone, V. Evaluating the uptake and intracellular fate of polystyrene nanoparticles by primary and hepatocyte cell lines in vitro. Toxicol. Appl. Pharmacol. 2010, 242, 66-78. [CrossRef] [PubMed]

9. Xia, T.; Kovochich, M.; Liong, M.; Zink, J.I.; Nel, A.E. Cationic polystyrene nanosphere toxicity depends on cell-specific endocytic and mitochondrial injury pathways. ACS Nano 2008, 2, 85-96. [CrossRef] [PubMed]

10. Geys, J.; Coenegrachts, L.; Vercammen, J.; Engelborghs, Y.; Nemmar, A.; Nemery, B.; Hoet, P.H. In vitro study of the pulmonary translocation of nanoparticles: A preliminary study. Toxicol. Lett. 2006, 160, 218-226. [CrossRef] [PubMed]

11. Kuhn, D.A.; Vanhecke, D.; Michen, B.; Blank, F.; Gehr, P.; Petri-Fink, A.; Rothe-Rutishauser, B. Different endocytotic mechanisms for nanoparticles in epithelial cells and macrophages. Beilstein J. Nanotechnol. 2014, 5, 1625-1636. [CrossRef] [PubMed]

12. Rebuma, F.; Tobias, A.O.; Heidrun, M. Identification of multiple cellular uptake pathways of polystyrene nanoparticles and factors affecting the uptake: Relevance for drug delivery system. Eur. J. Cell Biol. 2014, 93, 323-337.

13. Corner, S.D.; Schmid, S.L. Regulated portals of entry into the cell. Nature 2003, 422, 37-44.

14. Yan, Y.; Georgina, K.S.; Jangus, P.R.J.; James, P.B.; Frank, C. Engineering particles for therapeutic delivery: Prospects and challenges. ACS Nano 2012, 6, 3663-3669. [PubMed]

15. Wolfgang, Z.; Neil, A.F.; Adrian, M.R. In vitro uptake of polystyrene microspheres: Effect of particle size, cell line and cell density. J. Control. Release 2001, 71, 39-51.

16. Albanese, A.; Tang, P.S.; Chan, W.C.W. The effect of nanoparticle size, shape, and surface chemistry on biological systems. Annu. Rev. Biomed. Eng. 2012, 14, 1-16. [PubMed]

17. Dos Santos, C.; Varela, J.; Lynch, I.; Salvati, A.; Dawson, K.A. Quantitative assessment of the comparative nanoparticles-uptake efficiency of a range of cell lines. Small 2011, 7, 3341-3349. [PubMed]

18. Heather, H.; Nicole, D.; Arwyn, T.J.; Hanno, H.; Hamidreza, G.; Claus-Michael, L. Nanoparticle geometry and surface orientation influence mode of cellular uptake. ACS Nano 2013, 7, 1961-1973.

19. Saha, K.; Kim, S.T.; Yan, B.; Miranda, O.R.; Alfonso, F.S.; Shlosman, D.; Rotello, V.M. Surface functionality of nanoparticles determines cellular uptake mechanisms in mammalian cells. Small 2013, 9, 300-305. [PubMed]

20. Jong, A.K.; Christoffer, Å.; Anna, S.; Kenneth., A.D. Role of cell cycle on the cellular uptake and dilution of nanoparticles in a cell population. Nat. Nanotechnol. 2012, 7, 62-68.

21. Kawamoto, T.; Sato, J.D.; Le, A.; Polikoff, J.; Sato, G.H.; Mendelsohn, J. Growth stimulation of A431 cells by epidermal growth factor: Identification of high-affinity receptors for epidermal growth factor by an anti-receptor monoclonal antibody. Proc. Natl. Acad. Sci. USA 1983, 80, 1337-1341. [PubMed]

22. Lim, Y.J.; Jeon, S.R.; Koh, J.M.; Wu, H.G. Tumor growth suppression and enhanced radioresponse by an exogenous epidermal growth factor in mouse xenograft models with A431 cells. Cancer Res. Treat. 2015, 47, 921-930. [CrossRef] [PubMed]

23. Masui, H.; Castro, L.; Mendelsohn, J. Consumption of EGF by A431 cells: Evidence for receptor recycling. J. Cell Biol. 1993, 120, 85-93. [CrossRef] [PubMed]

24. Chinkers, M.; McKanna, J.A.; Cohen, S. Rapid induction of morphology changes in human carcinoma cells A431 by epidermal growth factors. J. Cell. Biol. 1979, 83, 260-265. [CrossRef] [PubMed] 
25. Elizabeth, S.H.; Spencer, B.G. Surviving cell death through epidermal growth factor (EGF) signal transduction pathways: Implications for cancer therapy. Cell Signal. 2006, 18, 2089-2097.

26. Kelf, T.A.; Sreenivasan, V.K.; Sun, J.; Kim, E.J.; Goldys, E.M.; Zvyagin, A.V. Non-specific cellular uptake of surface-functionalized quantum dots. Nanotechnology 2010, 21, 285105. [CrossRef] [PubMed]

27. Chithrani, B.D.; Chan, W.C. Elucidating the mechanism of cellular uptake and removal of protein-coated gold nanoparticles of different sizes and shapes. Nano Lett. 2007, 7, 1542-1550. [CrossRef] [PubMed]

28. Daukas, G.; Zigmond, S.H. Inhibition of receptor-mediated but not fluid-phase endocytosis in polymorphonuclear leukocytes. J. Cell. Biol. 1985, 101, 1673-1679. [CrossRef] [PubMed]

29. Fred, S.W.; Philippe, I.H.B. Fluorescence lifetime imaging of receptor tyrosine kinase activity in cells. Curr. Biol. 1999, 9, 1127-1130.

30. Bag, N.; Huang, S.; Wohland, T. Plasma membrane organization of epidermal growth factor receptor in resting and ligand-bound states. Biophys. J. 2015, 109, 1925-1936. [CrossRef] [PubMed]

(C) 2017 by the authors. Licensee MDPI, Basel, Switzerland. This article is an open access article distributed under the terms and conditions of the Creative Commons Attribution (CC BY) license (http://creativecommons.org/licenses/by/4.0/). 